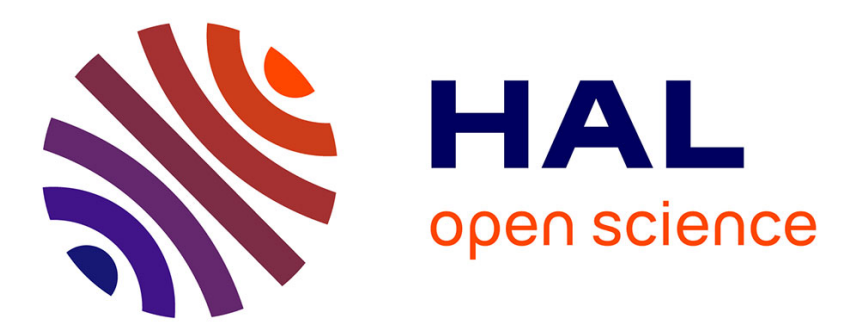

\title{
How to Find Disruptive Technologies Systematically?
}

\author{
Jianguang Sun, Zhitao Song, Kang Wang, Haoyu Li, Runhua Tan
}

\section{To cite this version:}

Jianguang Sun, Zhitao Song, Kang Wang, Haoyu Li, Runhua Tan. How to Find Disruptive Technologies Systematically?. 19th International TRIZ Future Conference (TFC), Oct 2019, Marrakesh, Morocco. pp.159-173, 10.1007/978-3-030-32497-1_14 . hal-02905541

\section{HAL Id: hal-02905541 \\ https://hal.inria.fr/hal-02905541}

Submitted on 23 Jul 2020

HAL is a multi-disciplinary open access archive for the deposit and dissemination of scientific research documents, whether they are published or not. The documents may come from teaching and research institutions in France or abroad, or from public or private research centers.
L'archive ouverte pluridisciplinaire HAL, est destinée au dépôt et à la diffusion de documents scientifiques de niveau recherche, publiés ou non, émanant des établissements d'enseignement et de recherche français ou étrangers, des laboratoires publics ou privés.

\section{(c)(1)}

Distributed under a Creative Commons Attribution| 4.0 International License 


\title{
How to Find Disruptive Technologies Systematically?
}

\author{
Jianguang Sun ${ }^{1 *[0000-0003-0138-1354]}$, Zhitao Song ${ }^{1[0000-0002-5496-2374]}$, Kang Wang ${ }^{1[0000-0002-}$ \\ 7881-1060], Haoyu Li ${ }^{1[0000-0001-8891-0479]}$ and Runhua Tan ${ }^{1[0000-0002-6797-8199]}$ \\ 1 Hebei University of Technology, Tianjin 300401, China \\ sjg@hebut. edu.cn
}

\begin{abstract}
This article describes an empirical study focusing on the systematic innovation process for finding disruptive technology opportunities. In the first part, the concept of the disruptive technology based on the bifurcation point of routes of system evolution of technology system is defined. The authors address three research questions. First, how does disruptive technology define? Second, what disruptive technologies of new product are most attractive in terms of interest from the customers from fuzzy front end of NPD? Third, in order to accurately find disruptive opportunities during the process of product detail design, how to establish models of function and find solutions from components of supersystem? The most notable achievement is a systematic flow constructed for achieving disruptive technologies systematically. Thus, the article provides a practical support for the methods to achieve disruptive technologies and the process is verified by case studies about copier and children's phone.
\end{abstract}

Keywords: Disruptive Innovation, Disruptive Technology, Model of Function, Supersystem Component.

\section{Introduction}

Disruptive innovation refers to the development of products whose performance is not as good as that of mainstream products but which have other characteristics of attracting insignificant users and new users [1-2]. From the beginning these products enter the low-end market or new markets, then gradually replace the finalized products of the mainstream market, and finally the enterprises that own these products will replace the incumbents [3]. This process is called disruptive innovation, and the technology used in new products is disruptive technology. Disruptive innovation products initially fail to meet the needs of mainstream customers because they may lack some features or functions of mainstream goods. However, they are typically simpler, more convenient, and less expensive. It is these characteristics that attract new users and existing low-end users, allowing emerging companies to enter the mainstream market to compete with incumbents. Disruptive innovation usually destroys the original market competition structure and constructs a new market pattern [4].

Danneels holds the view that disruptive technologies change the bases of competition because they introduce a dimension of performance along which products did not compete previously [5]. Adner states that as disruptive technologies mature they will 
alter industry boundaries by displacing established technologies from mainstream segments [6]. Christensen believes the industry's leading firms almost always triumphed in battles of sustaining innovation and that entrant firms typically beat the incumbent leaders when disruptive innovations emerged [7]. Hardman et al. mentioned the threat of the new technology is not often recognized by existing market leaders. Disruptive technologies are initially more expensive than the incumbent technologies. The quality of the disruptive technology initially is often worse than the quality of the technologies they seek to replace. The technologies have some form of 'added value' to the consumer [8]. Govindarajan and Kopalle hold the view that the disruptive-technology framework does indeed help us make ex ante predictions about the type of firms likely to develop disruptive innovations [9]. Bower and Christensen pointed out that the key is to manage strategically important disruptive technologies in an organizational context where small orders create energy, where fast low-cost forays into ill-defined markets are possible, and where overhead is low to permit profit even in emerging markets [10]. Bergek doubts the creative destruction of existing industries as a consequence of discontinuous technological change. He argues that creative accumulation requires firms to handle a triple challenge of simultaneously (a) fine-tuning and evolving existing technologies at a rapid pace, (b) acquiring and developing new technologies and resources and (c) integrating novel and existing knowledge into superior products and solutions [11].

Disruptive innovation is a special branch of technological evolution route. Unlike sustaining innovation, disruptive innovation technology does not pay much attention to promoting mainstream functions constantly. Technology forecasting based on technology evolution route can achieve the forecasting process of disruptive technology [12]. The implementation of disruptive innovation technology has two modes: requirement-driven and technology-driven. Requirement-driven originates from market, and disruptive innovation strategies are formulated in the light of the demand of new market. Technology-driven comes from the prediction of the technical status of the target product.

Although scholars have done a lot of research on disruptive innovation, its application still remains in the business model innovation in the field of management. Such innovation often solves the problem of fuzzy front end, and its implementation and verification are not clear enough [13]. In order to apply the process of disruptive innovation to the field of technological innovation, this paper proposes a systematic method of realizing disruptive innovation, which integrates disruptive technology as a solution into the solution set of innovative problem solving, effectively achieving the integration and application of multiple methods.

\section{Concept Definition}

\subsection{Disruptive Innovation Concept by Christensen}

The concept of disruptive innovation was first formally put forward by Clayton Christensen in his book The Innovator's Dilemma: When New Technologies Cause Great Firms to Fail and it has become a theory of technological innovation after the contin- 
uous improvement of later research [14-16]. Disruptive innovation refers to the introduction of products with lower performance than mainstream market products, but with some characteristics that attract unimportant users or new users. And with the development of these products, they can not only gradually gain a firm foothold in the low-end market and new market, but also replace the finalized products in the mainstream market. Companies that own these products, namely emerging enterprises, will replace incumbents, which means that disruptive innovation is completed. In terms of product technology evolution, the definition of disruptive innovation is summarized as follows: Disruptive innovation is a branch taking place on the route of product technology evolution, which occurs in the mature period of product life cycle, and the formation of this evolutionary branch make products have the ability to attract lowend users and new market users so that disruptive innovative products quickly form market scale and make a profit. It should be noted that although the performance of disruptive innovative products is poor in the introduction stage, it is generally cheaper, simpler, smaller, and more convenient to use. It is some of these features that enable them to compete with finalized products in the mainstream market. The disruptive innovation model and sustaining innovation model proposed by Christensen are shown in Fig. 1:

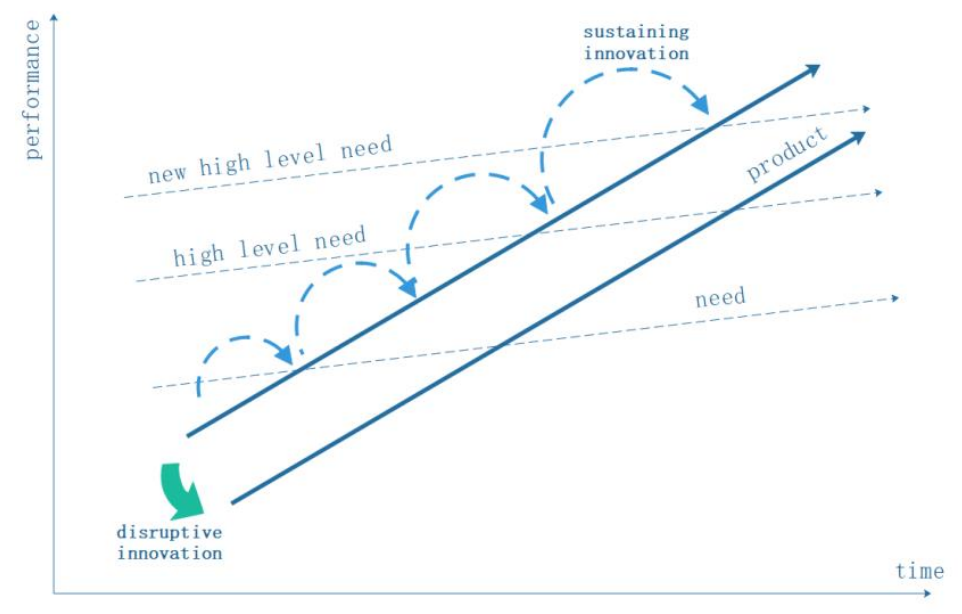

Fig. 1. Disruptive innovation model by Christensen

\subsection{Concept of DI based on technological evolution}

In order to adapt to the living environment, biological systems are constantly mutating and evolving, and the driving force of their evolution is the surrounding environment, that is, the so-called survival of the fittest. Similar to the process of biological evolution, products are constantly evolving [17] to adapt to market changes, and the market is driven by demand. In other words, product evolution is the result of adapting to current and future needs, and demand is the driving force of product evolution. Future demand promotes the evolution of current products, transforming their func- 
tions from the current state to the future state. To meet the constantly changing needs of the market and consumers, companies have designed ever-changing products. These products, similar to biological individuals, have genetic information that determines their structure, identity, and function, and have evolved from generation to generation. However, in order to capture the market in the future, it is not enough for enterprises to compete passively with their competitors, but to continuously develop the new market space with huge demand and realize the strategic action of "value innovation" [18-19]. This process is consistent with the concept of disruptive innovation proposed by Christensen. Therefore, we have redefined disruptive innovation in the field of technological evolution, aiming to improve the effectiveness of innovation, break away from the passive inherent evolutionary route, and make technological prediction of disruptive technology.

It is generally considered that innovation is divided into three categories: Incremental Innovation (II), Radical Innovation (RI), and Disruptive Innovation (DI). The evolution process of product technology is usually represented by a series of head-tail S-curves. It includes many evolutionary branches, and different branches of technological evolution determine the classification of innovation [20]. As shown in Fig. 2, the innovation process occurring on the same $\mathrm{S}$ curve segment usually involves solving local conflicts and improving performance, and has a fixed path of evolution [21]. This process is called Incremental Innovation, such as the technological innovation that happens from B to C in Fig. 2. During the exit state of the S-curve, the re-sources for improving the prior art have been exhausted, the technical performance has reached the limit, however, the market requirements cannot be met. At this time, new alternative technologies must be developed to achieve a breakthrough in technical performance and principles. This innovative process is called Radical Innovation [22], which is characterized by the end of one S-curve connected to the head of next adjacent S-curve, as shown in Fig. 2 (from C to D). Disruptive Innovation takes place in the mature period of the S-curve, and there are two types. One is the short-term retrogression of technological evolution, such as the technological innovation in the evolution process from B to A in Fig. 2. The other technological innovation is shown as a jump between different $S$ curves during the mature state (from B to E in Fig.2). The former is called Low-end Disruptive Innovation, while the latter is called New market Disruptive Innovation. 


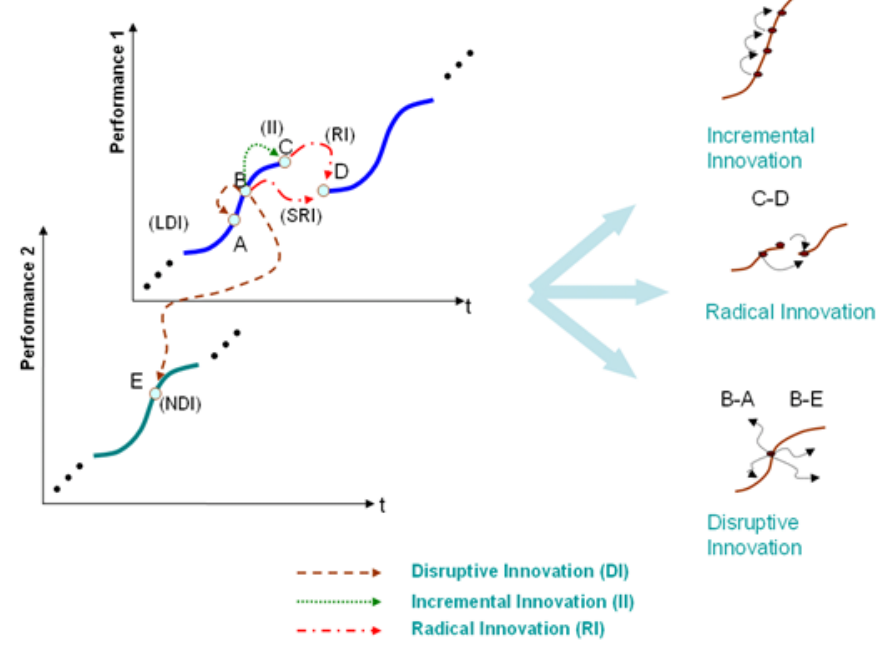

Fig. 2. Innovations in the process of technological evolution

\section{Systematic Methodology}

\subsection{Problem Definition}

The systematic product innovation process includes five stages: Fuzzy Front End (FFE), New Product Development (NPD), Conceptual Design, Detailed Design, Production Process and Commercialization, as shown in Fig. 3. During the fuzzy front end stage, various ideas should be generated based on market opportunities, and according to enterprise capabilities, several ideas should be determined through evaluation, and new product development projects should be launched on the basis of these ideas. After the subsequent conceptual design, detailed design, production process design and manufacturing, the ideas input in the previous stage are transformed into products and exported to the commercialization stage. After the operation of the market, the products are transformed into enterprise benefits in the commercialization stage, thus completing the whole process of effective product innovation.

Innovation is a complex process that needs to constantly solve the problems that arise at each stage. During the fuzzy front end stage, it is mainly about how to generate innovative ideas and how to make a choice from these ideas. In the product development phase, it mainly involves how to turn selected innovation ideas into real products and the problems at different stages of development are different. In the commercialization stage, it is mainly a question of how to carry out the commercialization operation so that the product can produce benefits. In the process of product innovation, technological innovation is mainly reflected in the stage of fuzzy front end and new product development, which realizes product innovation by constantly discovering and creatively solving the technical problems. With regard to the obsta- 
cles encountered in the stage of commercialization, on the one hand, it can be solved by management innovation methods, and at the same time, the technological environment of the society can be utilized to create more market-oriented approaches.

The disruptive innovation problem solved by Christensen is mainly concentrated in the fifth stage mentioned above, namely the commercialization stage. For the systematic innovation problem, it exists in the whole life cycle of the product, so the problems that arise in the remaining four stages also have the disruptive innovation solutions.

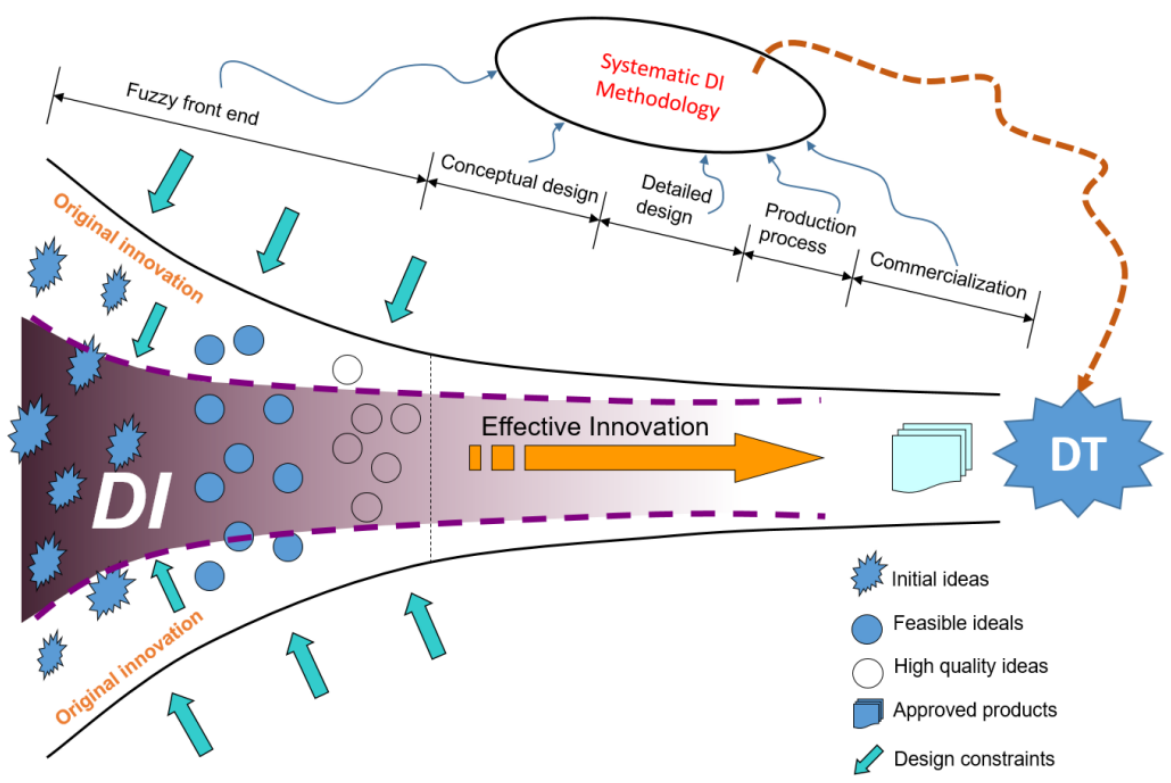

Fig. 3. The innovation process of products development

\subsection{DI process for Fuzzy Front End}

In a market environment full of risks and fierce competition, it is difficult for emerging enterprises to enter a mature market because incumbents already occupy a large amount of resources [23], such as technology, patents, markets, people and so on. For them, traditional incremental innovation cannot compete with incumbent enterprises, while radical innovation must solve the technical bottleneck problem of upgrading mature products in the industry, and emerging enterprises generally do not have this ability. For emerging enterprises, disruptive innovation is an effective meth-od. Only through disruptive innovation can they enter the market in the initial stage and change their passive position in the competition, which often occurs in the fuzzy front end stage of product development.

As shown in Fig. 4, it is a disruptive technology implementation process for the fuzzy front-end stage based on the analysis of technological system evolution. 


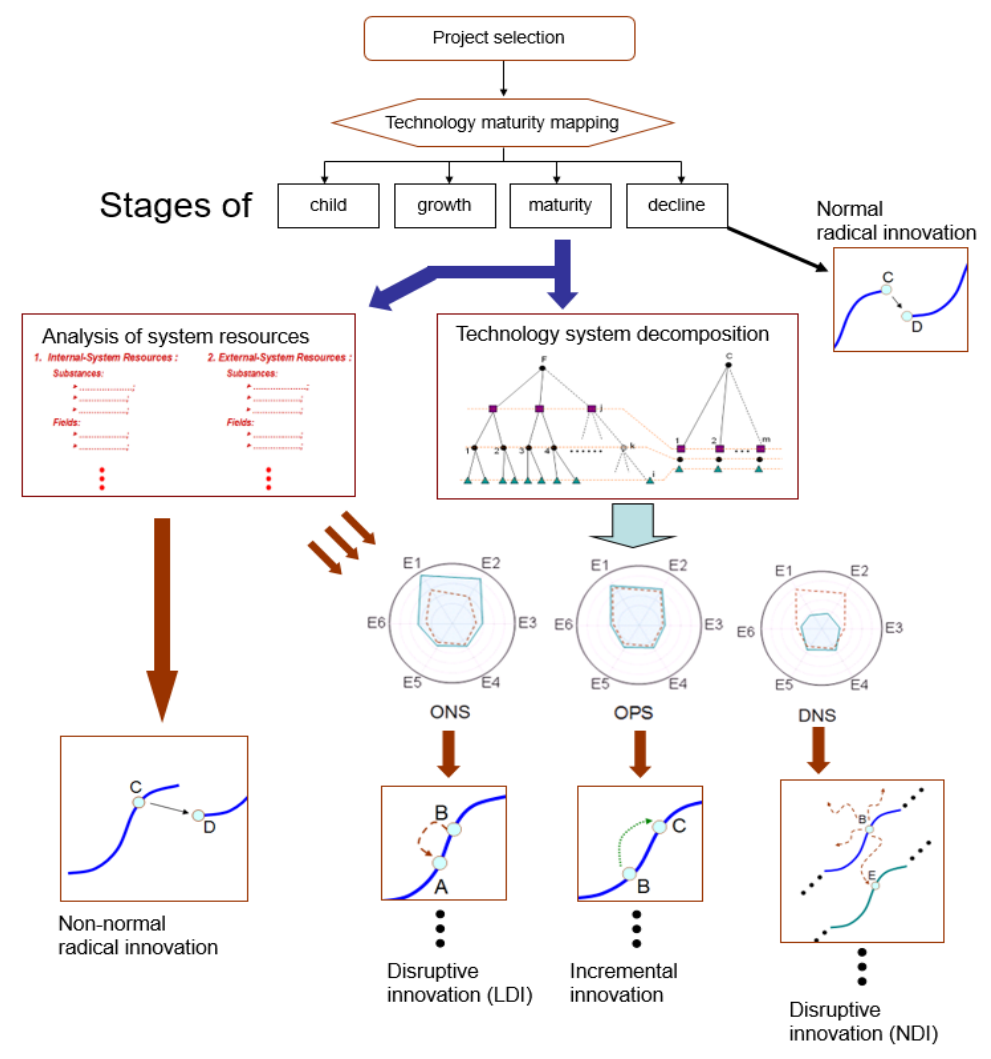

Fig. 4. Innovation process for the fuzzy front-end stage

First, according to the product structure of the enterprise, the innovation object is selected, and the technical maturity analysis of the innovation object is carried out. In the mature stage, products are facing fierce market competition. The performance improvement brought by incremental innovation is not obvious, and the cost performance is not high, but the implementation effect of disruptive innovation is pretty good. Therefore, products that are in mature period are preferred for disruptive innovation.

Second, the target product is decomposed into a number of technical systems. Similar to the functional structure of the product, the technical system that constitutes the product consists of subsystems at all levels. Each subsystem has a complete system structure, which can be analyzed as a complete technical system, resulting in multiple technical subsystems.

Third, demand evolution analysis is carried out. Aiming at a specific new market, the law of demand evolution is selected and used to determine the evolutionary direction of related technical subsystem functions. According to the principle of demand evolution and the designer's experience, the potential demand is predicted, and then the possible additional auxiliary functions are determined. Through market survey, 
the market demand of adding auxiliary function is investigated to prepare for the subsequent evolution analysis of the technical subsystem.

Fourth, carry out the evolutionary analysis of technical subsystem. By comparing the existing functional state of each technical subsystem with the result state of demand evolution analysis, the evolutionary state diagram of the technical subsystem is drawn. According to user demand, if the technology subsystem is in the over-satisfied need state (ONS), Low-end Disruptive innovation can be achieved by reducing excessive performance. If current or future new market user needs are in the dis-satisfied need state (DNS), the New market Disruptive Innovation strategy can be implemented.

Fifth, evaluate the design results. Evaluate the results of innovative design, mainly to assess whether it brings new technical conflicts, whether it causes the increase of costs, and whether it meets the market demand. After the evaluation, the product can enter the detailed design stage.

\subsection{DI process for design process}

Target of innovation is effective innovation. There exists many problems to be solved in the process of product design, so what is the target for solving these problems? Perhaps you will answer: The target is to improve the performance of the product, but for the enterprise, making profits is seen as the most important goal. If a product with excellent performance cannot bring benefits to the enterprise (because of high cost, complicated operation, high energy consumption, etc.), this product will be declared a failure. From the angle of innovation, this innovation is ineffective. In conclusion, in the process of product design, the target of solving the problem is to achieve effective innovation, that is to say, to bring expected benefits to enterprises.

Search technology opportunities based on effective innovation. The goal of the sustaining innovation process is to improve the performance of the product. The process of solving the problem is illustrated in Fig. 5. Define the problem first, then establish the function model [24-25] and carry out the root cause analysis. Determine the available resources of the system through resource analysis, and finally solve the problem by using the tool of TRIZ. But in the mature period of product evolution, the market competition is fierce, the available resources are scarce, and the improvement of performance often faces a large number of conflict problems that are difficult to resolve. In this case, effective innovation can be achieved by adopting a compromise method to eliminate conflicts and modifying the supersystem to meet user needs.

Function analysis for disruptive innovation: Complex user requirements are often achieved by a number of interrelated functions. In order to facilitate the search for a principle scheme that satisfies the total function of the product, or to make the solution of the problem simple and convenient, the total function is usually decomposed into sub-functions with relatively low complexity, and sub-functions are decomposed into next level sub-functions until they are decomposed into function units. The decomposition process is called functional decomposition. The total function of the product refers to the total relationship between input and output of the product or system to be designed. The entity that inputs and outputs is called a flow. After a high 
level of abstraction, the flow is divided into matter flow, energy flow, and information flow. The sub-function is a part of the total function, and its relationship with the total function is controlled by the constraint or the relationship between input and output. Function unit is the abstraction of existing components and processes. The substancefield model expresses the functions of two components through field interaction. The technical system is composed of different components interconnecting and interacting with each other. Every two interacting components can construct a substance-field model and all elements of the system form a complex material-field model system through field connections. And then the function model of the system can be established by expressing the "field" with "action".

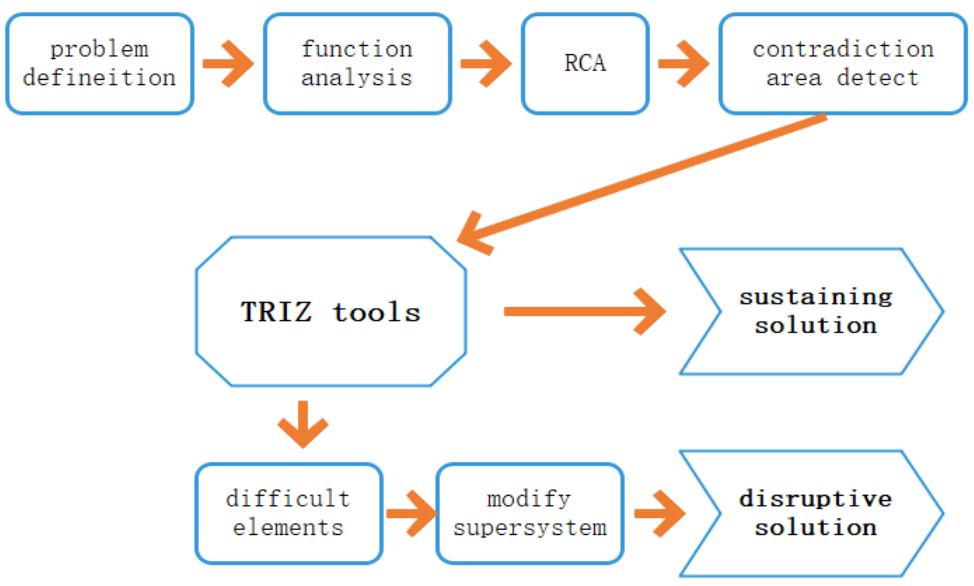

Fig. 5. Systemic innovation process of product

Any product can be represented by a function model. There are many problems encountered in the process of product design and improved design, and the process of solving these problems is the process of innovation. In the expression of a function model, there are products, components, supersystems, and the relationship between them. For example, as illustrated in Fig. 6, there is a problematic product that requires technological innovation to correct the insufficient effect a6 and harmful effect a11 (see Unit1). Under the guidance of the principle of TRIZ, such as conflict theory, standard solutions of substance-field, trimming, technological evolution and so on, components 2, 3, 5 have been changed, eliminating the insufficient effect a6 and harmful effect a11 (see Unit2). However, the above process of solving problems is a typical sustaining innovation process, the purpose of which is to improve the performance of the system, and changes to products and supersystems are not allowed. By changing products and supersystems, it is often possible to reduce the difficulty of solving problems and achieve disruptive innovation. As show in Fig. 6, low end disruptive innovation can be achieved by changing the product, and new market disruptive innovation can be realized by changing the supersystem (see Unit3).

The process method is as follows: 
First, describe the problem to be solved and clarify that the ultimate target of solving this problem is to achieve an effective innovation of the product.

Second, establish the system function model, which is composed of components, supersystems, products, and the interactions between them. Current system problems can be expressed as harmful or insufficient effects between components, between components and supersystems, and between components and products.

Third, after the root cause analysis (RCA), TRIZ tool is used to solve the problem of function model. If the solution process is not so complicated, multiple solutions can be obtained according to the steps of sustaining innovation.

Fourth, try to change the supersystem and adjust the corresponding components until the harmful and insufficient effects between the components are eliminated for obtaining a new solution and the corresponding disruptive innovation is formed.

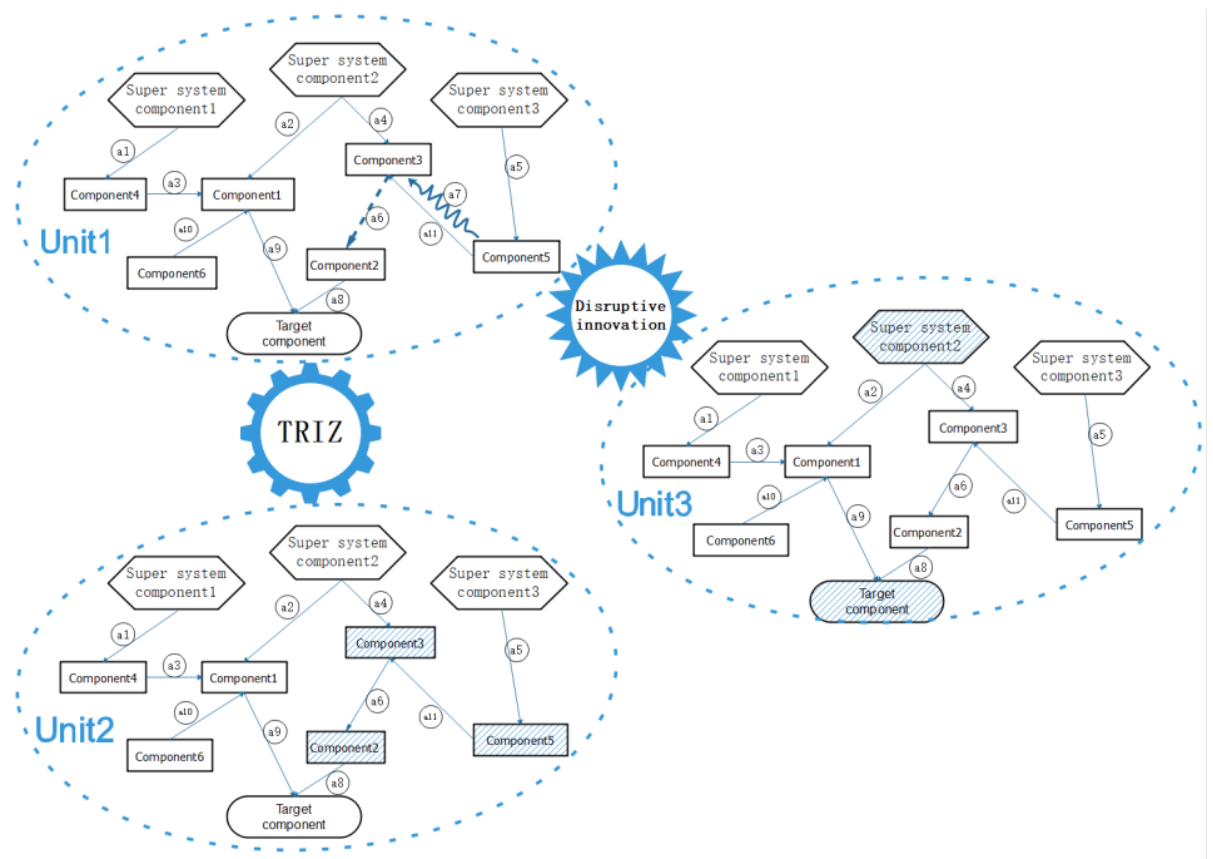

Fig. 6. Innovation process based on function model analysis

\section{Case study}

\subsection{Canon copier}

In 1976, Canon avoided the fierce competition in the Red Ocean market of large duplicators and entered the small duplicator market which everyone ignored and looked down upon. As a result, it created an amazing business myth in this Blue Ocean market, with almost no obstacles. From 1976 to 1981, Xerox's market share in the photocopier market plummeted from $82 \%$ to $35 \%$. Although it took Xerox more than a 
decade to deal with the threat of Canon's entry into home offices and small businesses, it was too late to shake Canon's leading position in the market. In this process, Canon adopted disruptive technology.

The function of a copier is to copy the original into multiple copies. The principle is as follows: Light shining on the item to be copied is reflected by the lens onto a photosensitive (selenium-coated) drum to form an image. The selenium drum's surface charge varies with the light and dark areas of the image. The toner drum delivers tiny black particles (toner) to the dark, charged areas of the image. The toner-based image is then transferred to the paper rolled onto the drum, the negatively charged toner particles being attracted by a positive charge under the sheet, and the paper is heated to fix the toner. The copy paper itself originally provided the treated surface, but the innovation of the selenium-coated drum made it possible to use the ordinary paper. Light projection permits the printed image to be enlarged or reduced by any desired percentage.

The function model of the Ricoh copier is shown in Fig. 7. The problem with current system is that it is necessary to further expand the market and improve the competitiveness of products. The main parameters of the copier are: copy speed, copy format and copy definition. In order to achieve this goal, it is necessary to modify each function unit to solve a large number of conflict problems. There are many difficult function units, which make the solution of the problem quite complex in this process. A compromise approach can be adopted to modify the supersystem and products so that problems can be solved and a disruptive innovation opportunity arises. The following steps are adopted:

1) Problem Description: New enterprises are supposed to develop a highperformance photocopier to form effective innovation if they are willing to enter the existing photocopier market.

2) The copier's function model is established, as shown in Fig. 7. In order to improve the performance of the copier, it is important to increase the copying speed, increase the copy size, and improve the clarity of the copy. Since the product is monopolized by the existing leading enterprises and the available resources are scarce, it is extremely difficult to solve the corresponding function model, which means that there is no way to form an effective solution of sustaining innovation.

3) Change the user which belongs to the supersystem. The former user is a professional operator for large and medium-sized enterprises, while the current user is transformed into a domestic user and a small company user. The problem of insufficient copy size can be solved, and the requirements of simple operation is put forward. Change the product to reduce the size of the paper to be copied. The above measures solve the problem of current performance improvement.

4) The resulting disruptive technology products are: a small, lightweight, inexpensive, and easy-to-operate copier for domestic users and small company users. Compared with mainstream engineering copiers in the market, it has low speed, small format, and low definition requirements. 


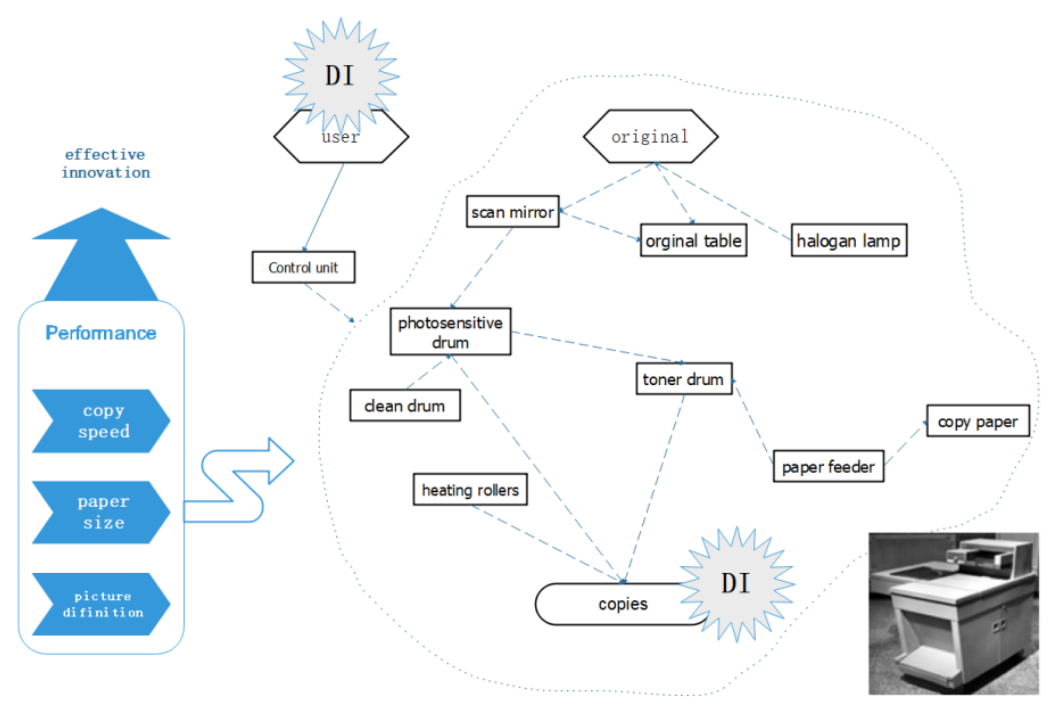

Fig. 7. Innovation process of copier

\subsection{Child's phone}

The functional model of smartphones is shown in Fig. 8. The existing problem of the current system is that the emerging enterprises want to enter the mobile phone market, but they are weak in technology and lack of funds. Therefore, there are a lot of difficult function units in the function model of the system. In the process of solving these difficult function units using traditional TRIZ theory, due to the lack of resources, the solving process can not be completed and effective innovation can not be achieved. Disruptive innovation methods can be used to change the supersystem and products of the system, so that problems can be solved and opportunities for disruptive innovation emerge. The following steps are adopted:

1) Problem Description: New enterprises need to develop a new mobile phone to enter the existing mobile phone market.

2) Establish the function model of mobile phone, as shown in Fig. 8. If we design according to the idea of improving the performance of mainstream products, we need to improve the performance of most of the key components. Because of the lack of resources in emerging enterprises, it will lead to the increase of costs and can not achieve effective sustaining innovation.

3) Change the user which belongs to the supersystem. The original user is aimed at the adult user market. By turning users into children, the problems of insufficient performance and high cost can be solved. Meanwhile, the requirements of simple operation, protecting eyesight and preventing addiction to games are put forward. Change the product. Replace the mainstream high-resolution touch screen with low-resolution small screen with a few function keys, and remove the photo function. 
4) The ultimate disruptive technology is: a special mobile phone with simple function, easy operation, low cost and no entertainment function for children users. On the basis of guaranteeing basic communication functions, compared with mobile phones in the mainstream market, children's mobile phone has low cost, simple structure and low performance requirements. It avoids fierce competition with the mainstream market of mobile phone and opens up the Blue Ocean market.

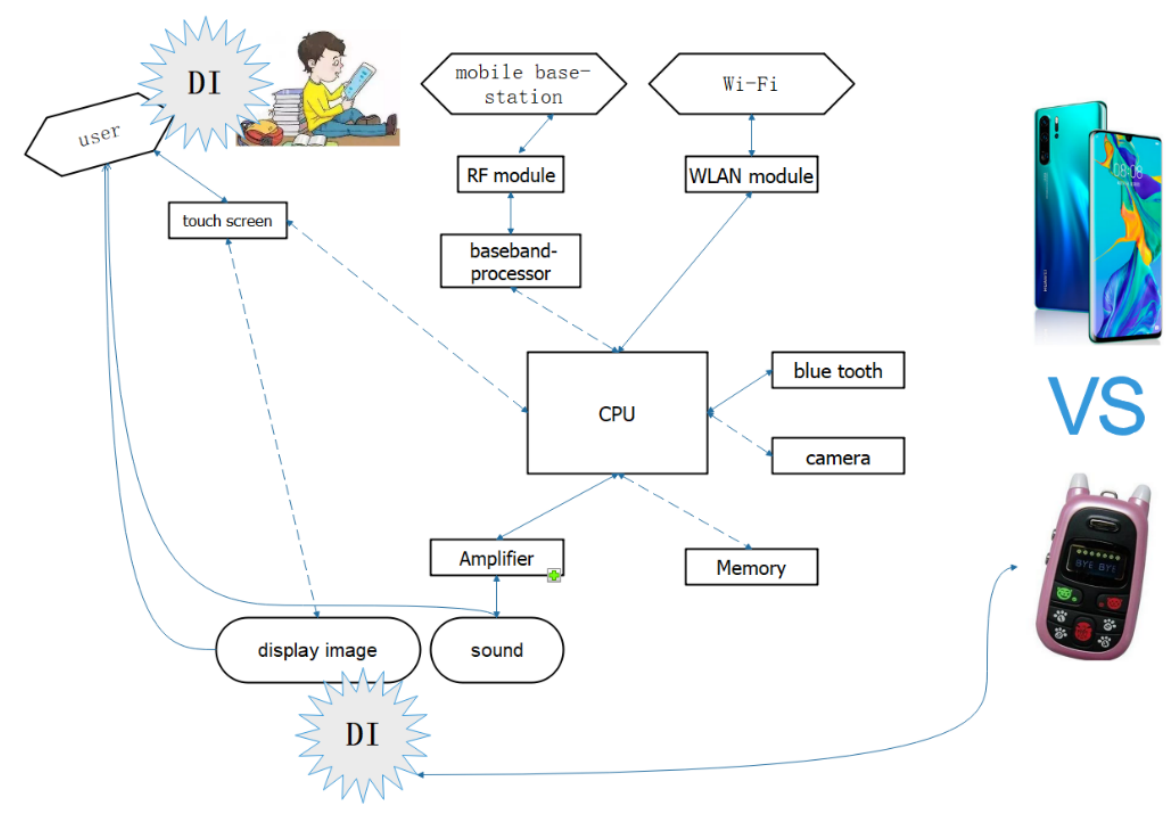

Fig. 8. Innovation process of Child's phone

\section{Conclusion}

In this study, disruptive technology is introduced into the process of product technology innovation, which enlarges the application scope of this technology. It is not only applied to the business model innovation in the field of management, but also used in the field of technology innovation, which is a complement to the traditional innovation methods. It is reflected in the following points:

1) In the process of solving problems with TRIZ, if the resources are insufficient, it will make it extremely difficult to solve the problem, and sometimes the problem cannot be solved. The application of this method can effectively solve the problem of insufficient innovation resources, and introduces a large amount of available resources through changes to the supersystem.

2) The problem of solving difficult function units is solved by disruptive innovation technology. Difficult function unit is a great obstacle to solve problems by using TRIZ. The application of this method changes the attributes of difficult function 
units by changing supersystems and products, so that they are no longer obstacles to innovation.

3) The usual process of sustaining technological innovation is dedicated to solving the problems in technical systems by eliminating the insufficient and harmful effects of the system with TRIZ tools. Changes to supersystems and products are not allowed in this process. The method proposed in this study allows modification of supersystems and products based on the target of effective innovation.

\section{Acknowledgements}

This research is supported by the National Innovation Method Fund of China (2017IM040100), Erasmus+ Programme of European Union (586081-EPP-1-2017-1FI-EPPKA2-CBHE-JP), the Natural Science Foundation of Hebei province of China (Grand No.E2017202260).

\section{References}

1. Adner, R.: When are technologies disruptive? A demand-based view of the emergence of competition. Strategic Management Journal 23(8), 667-688 (2002).

2. Christensen, C. M.: The innovator's dilemma: When new technologies cause great firms to fail. Harvard Business School Press, Boston (1997).

3. Christensen, C. M., Baumann, H., Ruggles, R.: Disruptive innovation for social change. Harvard Business Review 84(12), 94-101, 163 (2007).

4. Christensen, C. M., Rosenbloom, R. S.: Explaining the attacker's advantage: Technological paradigms, organizational dynamics, and the value network. Research Policy 24(2), 233257 (1995).

5. Danneels, E.: Disruptive technology reconsidered: A critique and research agenda. Journal of Product Innovation Management 21(4), 246-258 (2010).

6. Adner, R., Zemsky, P.: Disruptive technologies and the emergence of competition. RAND Journal of Economics 36, 229-254. 10.2139/ssrn.293686 (2005).

7. Christensen, C.M.: The ongoing process of building a theory of disruption. Journal of Product Innovation Management 31(1), 39-55 (2005).

8. Hardman, S., Steinberger-Wilckens, R., Dan, V.: Disruptive innovations: The case for hydrogen fuel cells and battery electric vehicles. International Journal of Hydrogen Energy 38(35), 15438-15451 (2013).

9. Govindarajan, V., Kopalle, P. K.: The usefulness of measuring disruptiveness of innovations ex post in making ex ante predictions. Journal of Product Innovation Management 23(1), 12-18 (2005).

10. Bower, J. L., Christensen, C. M.: Disruptive technologies: Catching the wave. Harvard Business Review 73(1), 43-53 (1995).

11. Bergek, A., Berggren, C., Magnusson, T.: Technological discontinuities and the challenge for incumbent firms: Destruction, disruption or creative accumulation?. Res. Policy 42(67), 1210-1224 (2013).

12. Sun, J., Tan, R.: Method for forecasting DI based on TRIZ technology system evolution theory. International Journal of Innovation and Technology Management 9(02), 1250010 (2012). 
13. Reinhardt, R., Gurtner, S.: The overlooked role of embeddedness in disruptive innovation theory. Technological Forecasting and Social Change 132, 268-283 (2018).

14. Christensen, C., Raynor, M.: The innovator's solution: Creating and sustaining successful growth. Harvard Business School Press. Boston (2003).

15. Christensen, C. M., Bower, J. L.: Customer power, strategic investment, and the failure of leading firms. Strategic Management Journal 17(3), 197-218 (1996).

16. Christensen, C.M., Overdorf, M.: Meeting the challenge of disruptive change. Harvard Business Review 78 (1), 67-76 (2000).

17. Nelson, R. R., Winter, S.: An evolutionary theory of economic change. Social Science Electronic Publishing 32(2) (1982).

18. Kim, W.C., Mauborgne, R.: Blue Ocean strategy: How to create uncontested market space and make the competition irrelevant. Harvard Business School Press, Boston (2005).

19. Kim, W.C.: Blue Ocean strategy: From theory to practice. California Management Review 47(3), 105-121 (2005).

20. Sun, J., Tan, R.: Methods for roadmapping mutational innovation based on technological evolution bifurcations. Computer Integrated Manufacturing System 19(2), 253-262 (2012).

21. Sun, J., Tan, R., Guo, J.: Research on IFR of technological evolution bifurcations. TRIZ Future Conference, 377-390. Paris, France (2013).

22. Sood, A., Tellis, G. J.: Technological evolution and Radical Innovation, Journal of Marketing, Vol.69, Issue 3, 152-168 (2005).

23. Zlotin, B., Zusman, A.: The concept of resources in TRIZ: Past, present and future. Ideation International, USA (2005).

24. Altshuller, G.: The innovation algorithm: TRIZ, systematic innovation and technical creativity. Technical Innovation Center, Worcester (1999).

25. Altshuller, G.: Creativity as an exact science: The theory of the solution of inventive problems. Gordon and Breach Science Publishers, New York (1984). 